\title{
Demand Responsive Route Design: GIS Application to Link Downtowns with Expansion Areas
}

\author{
Mintesnot Gebeyehu and Shin-ei Takano \\ Hokkaido University, Sapporo, Japan
}

\begin{abstract}
The movement of residential locations to suburban areas to obtain cheaper land results in increasing mobility and infrastructure problems. One of the important infrastructures is transportation, which determines the level of accessibility of people and commodities from one place to another. Therefore, Transportation Demand Management (TDM) measures are important in providing an optimal transit route to increase accessibility of public transportations. In the past, several researchers have developed various TDM programs, including public transport improvement as a strategy to encourage a more transit-oriented society. This study attempts to create a methodology of identifying bus links between urban centers and newly developed urban expansion areas using Geographical Information Systems by considering reduction of route overlapping. A TAZ-based analysis is undertaken to identify the demand responsive bus routes, which maximize population coverage, minimize travel time, and reduce duplicating routes.
\end{abstract}

\section{Introduction}

The competition for land makes residential developments more difficult to undertake in urban centers. The limited ability of residents, particularly low- and middle-income people, to pay for housing forces housing developments to be car- 
ried out in suburban areas at a cheaper price. The movement of residential locations to suburban areas to obtain access to land results in problems of increasing mobility and infrastructure demand. One of the infrastructures is transportation, which determines the level of accessibility of the people and commodities from one place to another (Kuswara et al. 2006). Therefore, Transportation Demand Management (TDM) measures are important for providing optimal transit routes and for increasing the accessibility of public transportation.

In the past, several researchers have developed various TDM programs. Among these programs are improvements to public transport as a strategy to encourage a more transit-oriented society (online TDM encyclopedia, updated November 2006). In this regard, different approaches have been implemented to identify the optimal route, including the emerging technique of Geographical Information Systems (GIS) application. Verma and Dhingm (2003) discussed a model that identified demand-oriented urban rail transit corridors on a city road network using GIS. Likewise, Sekhar et al. (2003) implemented a route-based analysis for optimized bus route design using GIS. The analysis was based on maximizing population coverage along transit routes, transit coverage to trip-attraction centers, access for residents in low-income dwellings along the transit route, and the transit level of service (frequency). Unlike the route-based analysis, Ramirez and Seneviratne (1996) implemented zone-based GIS transit route design by estimating the potential ridership for each zone and assigning scores to the street links. The same types of route design analysis have been developed with different objective functions (Sulijoadikusumo and Nozick 1998; Abkowitz et al. 1990; Ramirez and Seneviratne 1996).

Despite the previous studies conducted, the objective of reducing route overlapping has gained little attention. This study attempts to create a methodology of identifying a bus link between urban centers and the newly developed urban expansion areas using GIS by considering minimization of route overlapping, maximize population coverage, and minimize travel time.

\section{Public Transportation Demand}

\section{Case Study Area}

The case study examines Addis Ababa, the capital city of the Federal Democratic Republic of Ethiopia, located in the center of the country. Established in 1886, the city has experienced several planning changes that have influenced its physical 
and social growth. In the city of Addis Ababa, the dominant public transportation modes are city buses (40\%) and mini vans or small taxis (60\%), both of which are entirely limited in delivering service to the inner and intermediate parts of the city (Ethiopian Road Authority [ERA] 2005). Buses, operated by a solitary public company, have 30 seats but a carrying capacity of 100 people in crowded situations, whereas taxis, run by a private association, have a carrying capacity of 4 (small taxis) to 12 (minivan taxis) people. No rail transit or bus rapid transit (BRT) operates within the city. Car ownership is low, though growing quickly, so residents largely depend on buses and taxis for their day-to-day mobility. Walking is used for short trips only. Unlike other cities in Ethiopia, bicycle use is insignificant because of topographic inconvenience. Analysis of the transit availability indices show that only the city center is served by the existing bus networks, leaving urban expansion areas with low transit availability (Mintesnot and Takano 2006).

\section{The Demand}

According to two surveys (one is a trip survey of 750 households in inner, intermediate, and periphery areas, conducted in September 2004 by the authors of this article; the other is a survey of 5,000 households conducted by the ERA in December 2004), an estimated 3,348,317 person trips per day are made, on average, in the city of Addis Ababa. The overall per capita trip rate (PCTR), including persons of all age groups, is 1.07 (including walking trip) and 0.43 (excluding walking trips). When people between the ages of 0 to 5 are excluded, the PCTR increases to 1.141 and 0.451 with and without walking trips, respectively. This indicates that limited transport accessibility occurs in the city despite the prevailing high demand. Except for the three subcities, which are considered intermediate zones, the share of buses in the city ranges from 11 percent to 15 percent. Walking is the dominant mode if all short trips are considered (60.5\%). However, according to the general analysis results of our survey, 64 percent of the respondents use bus as their typical mode of transportation, 18 percent use taxi, and 12 percent walk. The remaining respondents stated using other modes of transportation such as a private car. The share of trips by minivans and small taxis varies widely among the subcities, with the inner city having a high share of 32 percent and the peripheral area experiencing a low share of 12.2 percent. When trip length is concerned, bus and minivan taxi travel time accounts for up to 90 minutes. The majority of the residents have an in-bus time of 50 to 60 minutes.

Generally, travel demand is as high as $\mathbf{1 1 . 0 5}$ million passenger-km on an average day. Of this, walking accounts for 27.3 percent. Buses and taxis account for 25 
percent and 34 percent, respectively, indicating their role and importance in the city. Trip characteristics of all trips in the city indicate a wide dispersal pattern. However, movement to and from central areas is reasonably high. Walking trips are confined within the subcity or to and from adjacent subcities. Trips made by city bus or minivan have a wide-ranging pattern because they create interaction among the subcities (ERA 2005; Mintesnot and Takano 2006).

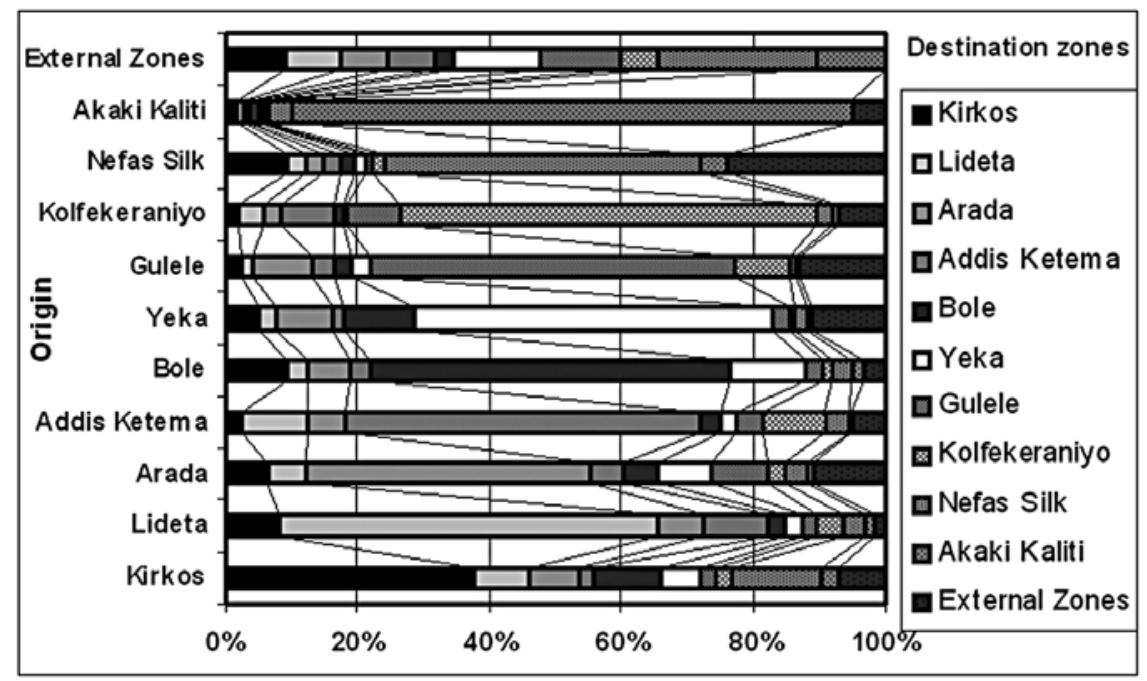

Figure 1. O-D Matrix of All Trips 


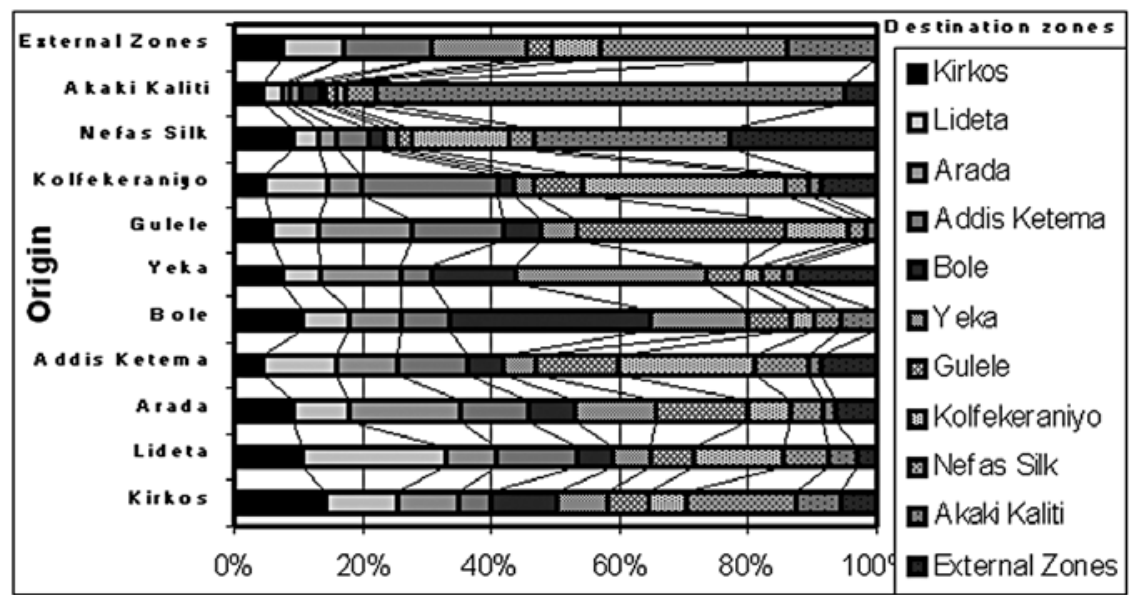

Figure 2. 0-D Matrix of Bus and Taxi Trips

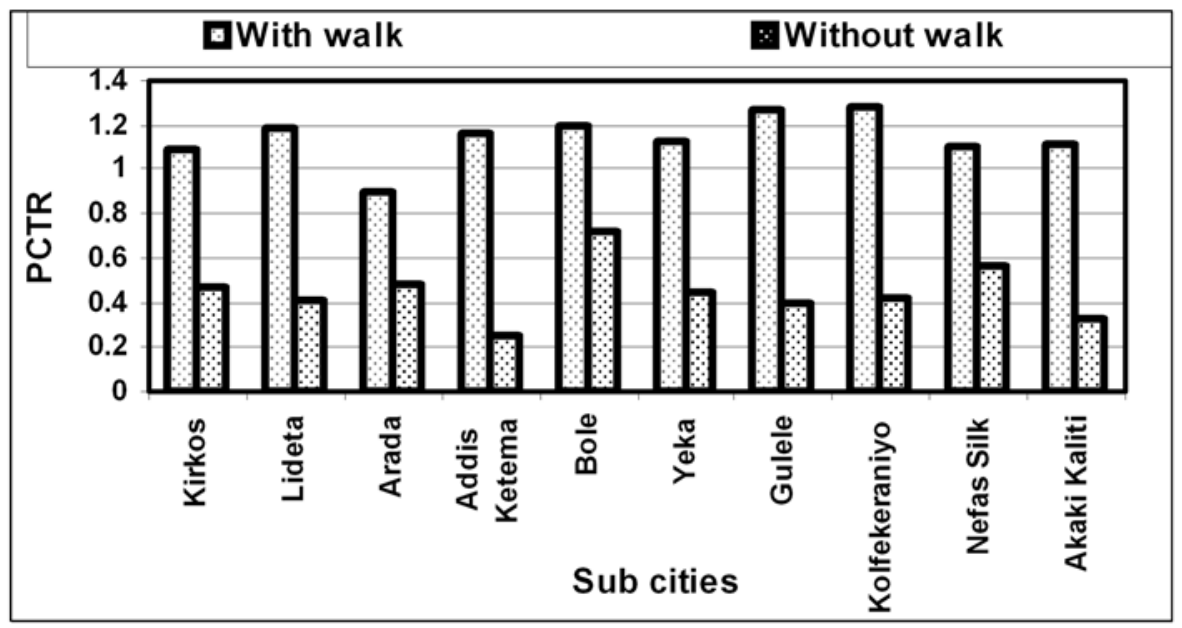

Figure 3. Per Capita Trip Rate, with or without Walking Trips 


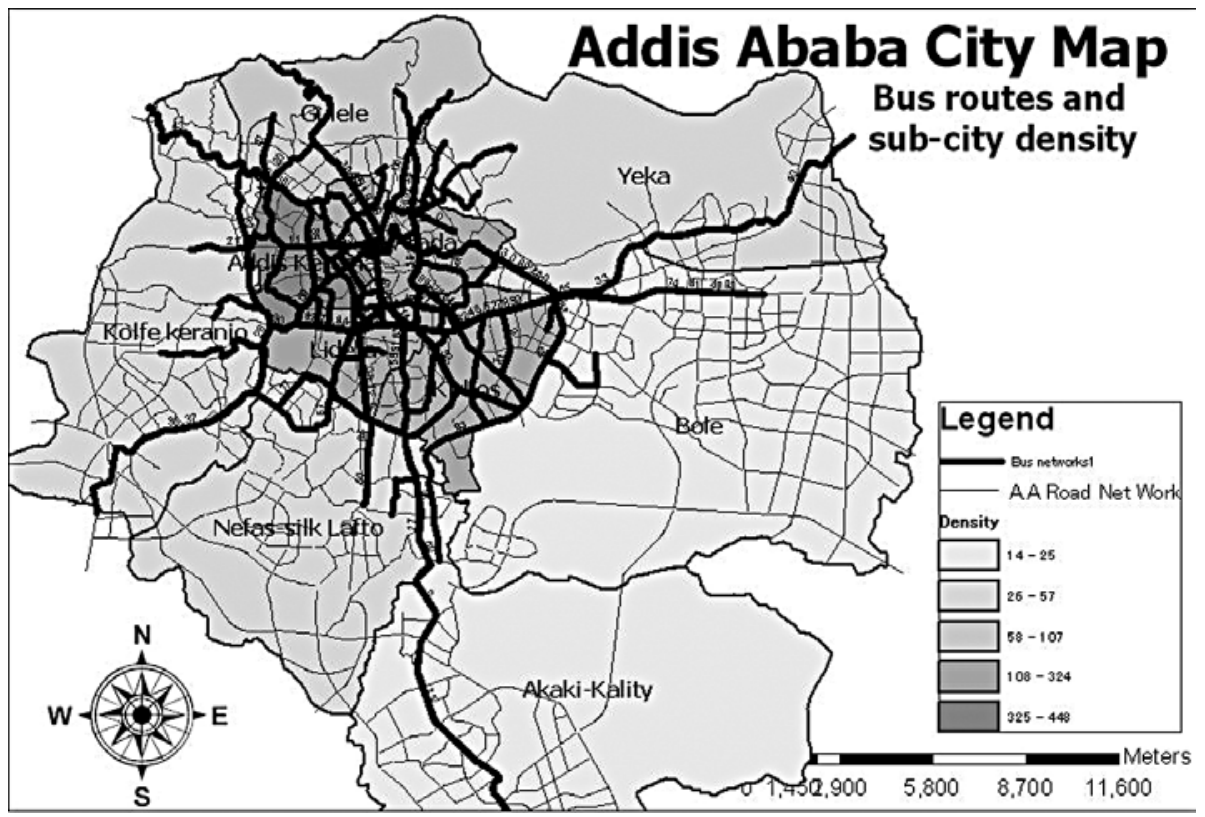

Figure 4. Addis Ababa City with Subcity Divisions

The uncontrolled urban growth also creates potential trips from the suburb to the inner cities. From 1984 to 1994, 14,794 illegal/informal houses were developed in the urban peripheries (accounting for $15.7 \%$ of the total housing stock). Since 1999, government-initiated housing projects through cooperatives and individual housing constructions schemes have been developed. In 2000, the regional government issued a legalization policy for informal settlements; municipal offices provided utilities such as electricity and water. These urban expansions created a potential trip generation to city centers where commercial and economic activities take place. Despite the growth in travel demand, no considerable expansion of public transportation occurred. Studies of public transportation strategies within the city, such as provision of BRT and light rail, have been undertaken (ERA 2005; Mintesnot and Takano 2006; ORAAMP 2002); however, implementation is constrained by financial problems of the regional and national governments. As an immediate action for tackling the existing travel demand by expanding the existing bus services, the government and the bus company must consider route expansion proportionate to the city's growth. With this problem in mind, this 
study's objective is to provide a methodology for linking urban centers (economic and employment centers) to the residential areas in the suburbs.
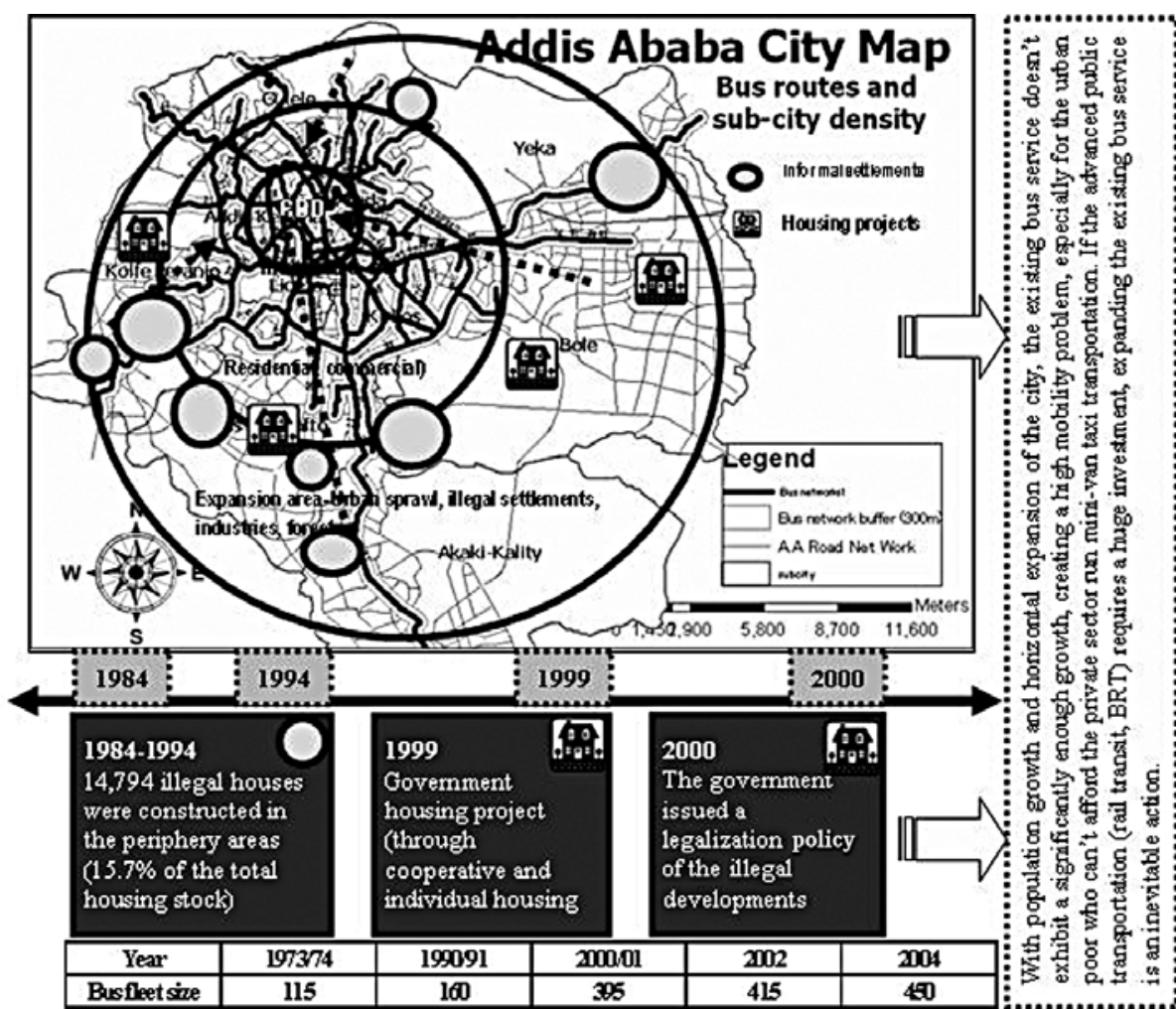

Figure 5. Synthesis of Urban Expansion vis-à-vis Public Transportation Demand

\section{Demand Responsive Route Design: GIS Application}

\section{Methodology}

The methodology of connecting the innercity with the new neighborhoods is undertaken by a route-searching mechanism of maximum population areas and areas with minimum route overlapping. The Traffic Analysis Zone (TAZ)-based approach assigns the existing route characteristics with respect to the TAZ and the TAZ's population to the street links and calculates route impedance factors. 


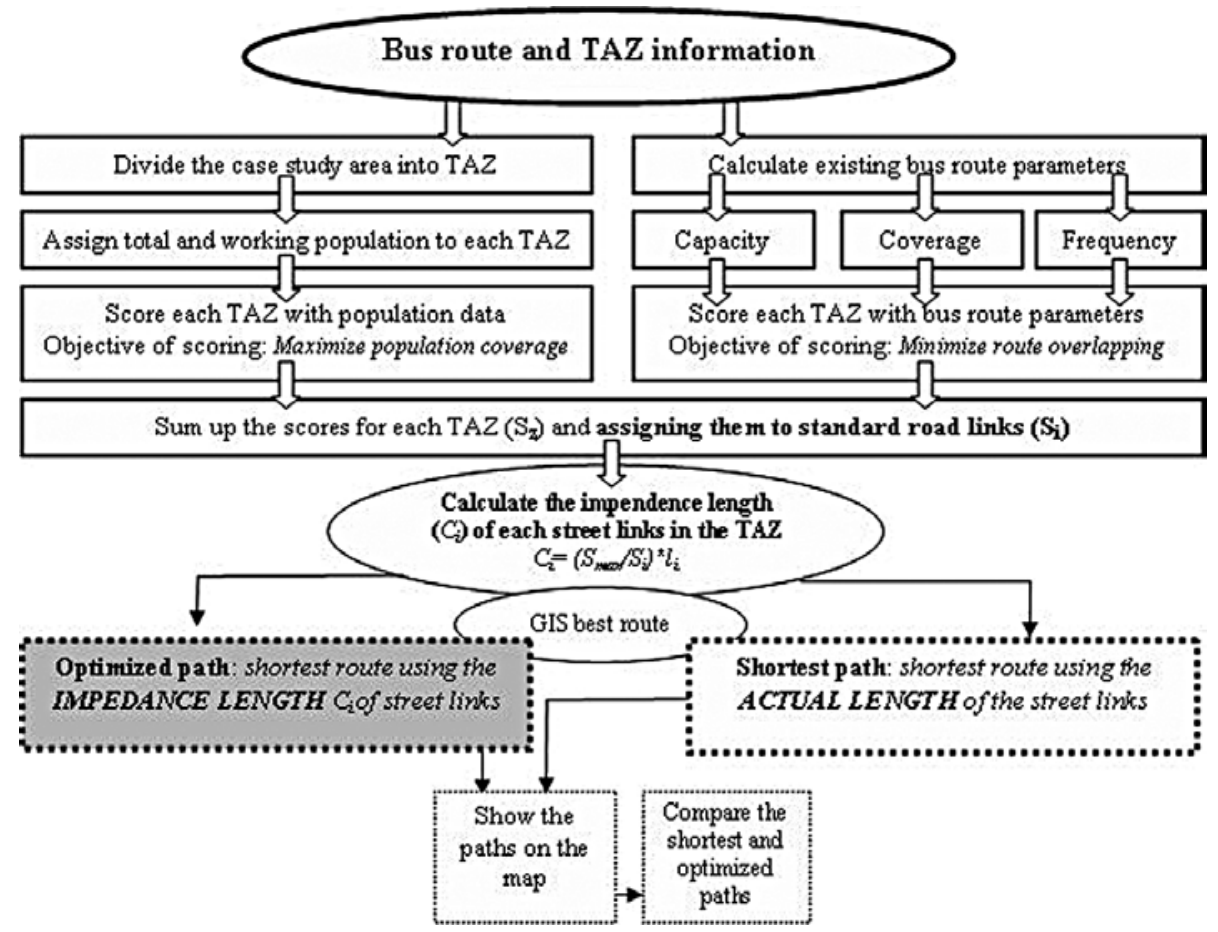

Figure 6. Framework of the Proposed Method

For this, Addis Ababa is divided into $308 \mathrm{TAZs}$, which cover an average area of 1.56 square kilometers. The bus and road network and bus stops were digitized using GIS. Bus capacity data was provided by Anbessa City Bus Enterprise, and the population of each zone was collected from the city's administration office. The area of each TAZ was calculated using GIS, and baseline data were prepared for the three bus service components: capacity, coverage, and frequency. The Network Analyst extension of ArcView was applied for optimum route searching.

\section{Objective Functions and Route Design Parameters}

The first step of implementing this proposed approach is to define the objective functions and route design considerations. The objective functions are the most important, but sometimes conflicting functions of the route design occur. The transit operator chooses the shortest path to minimize operating costs; however, the shortest path is not always the maximized route. Travelers always choose the shortest walk from their trip origin (e.g., home) to the bus stops and the shortest 
in-vehicle time from their origin to destination. Additionally, the optimum route should keep the required route spacing and reduce route overlapping. Therefore, this study's three objective functions are:

- $\min \{T T\}$ : minimize travel time by providing the shortest possible path.

- max\{pop, density, employee\}: maximize overage of trip generation areas.

- $\min \{R O\}$ : minimize route overlapping/duplication.

Route design is based on certain parameters, such as the overall and working populations, existing bus route coverage, frequency, and capacity.

Minimize Travel Time: $\min \{\mathbf{T T}$. The basic objective of any optimization approach is to minimize the travel time, which includes waiting, in-vehicle, and walking times. Passengers choose the route to their destination based on the shortest travel time. Several shortest path algorithms have been developed in various forms to find the shortest possible path in the given network. One of the classical and widely used algorithms is Dijkstra's algorithm (see Osegueda et al. 1999): let $c_{i j}>0$ be the length of $\operatorname{arc}(i, j)$. It is desired to find the shortest route from a source node "o" to a terminal node " $\mathrm{d}$ " through the arcs of the network. Define a label for node $j$ as the estimate (temporary or permanent) of the length of the shortest path from the source to node $j$. If the node label is temporary, it will be represented by $\delta$; if it is permanent, by $[\delta j]$. Permanent labels represent lengths of the actual shortest paths.

- Step 0: $[\delta o]=0 ; \delta i=c_{o i}$

- Step 1: $[\delta j]=\{\delta i\} \min$

$i \in \mathbf{T}$

j: last node to get a permanent label

T: set of nodes with temporary label

- Step 2: If $[\delta d]$ is found, stop; otherwise, go to step 3

- Step 3: New $\delta i=\min \{$ old $\delta i ;[\delta i]+c j i\}$ for $i \in \mathbf{L}$

L: set of unlabeled nodes reached from last permanently labeled node

- Step 4: Go to step 1

This shortest path algorithm is embedded in the GIS shortest path finder, if the optimization objective functions are properly designed. The important question here is whether the shortest possible path is the best route. As stated previously, route designs often have conflicting and multiple criteria. Therefore, the following 
sections focus on formulating the shortest possible path, with the maximum route attraction coverage and minimum route overlapping.

Maximize Trip Generation Coverage: $\max$ \{pop, density, and employee\}. Population density is the best representation of the potential point of origin, in terms of daily trips. Employment density represents the number of jobs per square $\mathrm{km}$. Typically, work trips account for well over half of a transit system's ridership (Transport Research Board 1995). Sekhar et al. (2003), in their work, "An Approach to Transit Path Design using GIS," considered trip generators based on dwelling units as the main sources of trip productions. Other studies, however, considered the population along the route or in the TAZ. In this study, the total and the working populations in a given TAZ are considered, so that the TAZ will be scored according to the population (i.e., the larger the population the higher score given to the TAZ), which lead us to the maximization process as seen later, in which the score will be assigned to the street links in each TAZ.

Minimize route overlapping: $\min \{\mathbf{R O}\}-$ (Serve the underserved area). This criterion refers to a situation where two or more distinct routes, serving the same passenger market(s), appear within close or overlapping proximity. Streamlining/ reduction is designed to control the duplication of bus routes thereby ensuring transit services are adequately distributed geographically within a service area. By ensuring this, services can be more widely dispersed throughout neighborhoods (Transport Research Board 1995). This current research considers the minimization of route overlapping with the principle of serve the underserved area. Some urban locations have several bus routes passing through, while other localities suffer from the unavailability of transit routes. Therefore, in an effort to connect the innercity with the newly developed neighborhoods, route overlapping issues must be addressed. To achieve this, the three service features of existing bus routes (bus coverage, frequency, and capacity) are chosen, after which the TAZs are scored with coefficients of the chosen bus service features in such a way that a minimum coefficient creates a higher score for the TAZ; the score will be assigned later to the street links in the TAZ.

\section{Bus Route Coverage, Frequency, and Capacity}

The Local Government Commission of the United States, as an experimental measure, first introduced the Local Index of Transit Availability or LITA (Rood 1998). In this study, bus availability and bus service intensity are combined to create a City Index of Bus Availability or CIBA. The focus here is on buses, because they are the only transit option for Addis Ababa, as no rail service operates within the city. 
CIBA combines three aspects of transit service intensity-capacity, frequency, and route coverage - to rate each TAZ. The capacity component uses seat-km divided by population; the frequency component is calculated as the number of buses per day; the route coverage component uses transit stops per square kilometer. After normalizing the index, the amount of transit service available is related to that area's population and land area.

Bus capacity. Capacity can be defined in different terms such as vehicle capacity, person capacity, maximum capacity, and design capacity (see Transport Research Board 2003 for definitions). Person capacity is used in this study. This capacity component is the calculation of seat-km per capita. The total amount of daily bus seats is calculated as a product of the total number of buses arriving at a specific stop in the TAZ, and the number of seats on the bus.

where:

$$
\mathrm{C}_{\mathrm{TAZi}}=\frac{B S \times l_{\text {TAZi }}}{\operatorname{Pop}_{\text {TAZi }}}
$$

$\mathrm{C}_{\text {TAZi }}$ is capacity score in the ith TAZ

BS equals total daily bus seats

$1_{\mathrm{TAZi}}$ represents route length

Pop $_{\mathrm{TAZi}}$ equals population in $\mathrm{TAZ}_{\mathrm{i}}$

Bus route frequency. This parameter refers to the headway between two consecutive buses (the waiting time for the travelers). Frequency measure is based on the total daily number of buses on all the lines that have at least one stop or station in the TAZ.

$$
\mathrm{F}_{\mathrm{TAZi}}=\mathrm{TB} \text {, if } \mathrm{l}_{\text {TAZi }} \text { has at least one stop in TAZi; 0, otherwise }
$$

where:

$\mathrm{F}_{\mathrm{TAZi}}$ is frequency score in the ith TAZ

TB equals total number of buses 
Bus coverage. The bus coverage component of the transit availability analysis focuses on the spatial distributions of the existing bus service in the city, and is calculated based on the density of transit stops or stations.

where:

$$
\mathrm{CO}_{\mathrm{TAZi}}=\frac{S_{T A Z i}}{A_{T A Z i}}
$$

$\mathrm{CO}_{\mathrm{TAZi}}$ is coverage score in the ith TAZ

$\mathrm{S}_{\mathrm{TAZi}} \quad$ represents number of bus stops

$\mathrm{A}_{\text {TAZi }} \quad$ is area of the TAZ

The three scores are then added up for each TAZ, while the mean and standard deviation are calculated, thereby standardizing the score.

Standardized score $=([$ capacity, frequency or coverage score $]-$ [mean of distribution])/[standard deviation].

The overall CIBA score of each analysis zone can be calculated and the result can be joined with the map to represent which areas are well served or underserved by the existing bus supply.

Overall CIBA score $=([$ capacity score $]+[$ frequency score $]+[$ bus coverage score]).

At this point, rescaling the CIBA score is essential for greater ease of interpretation. To make all values positive, 5 was added to the overall score (see Figure 10). 


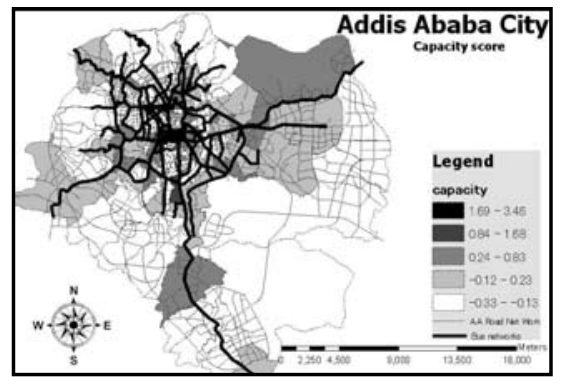

Figure 7. Capacity Scores

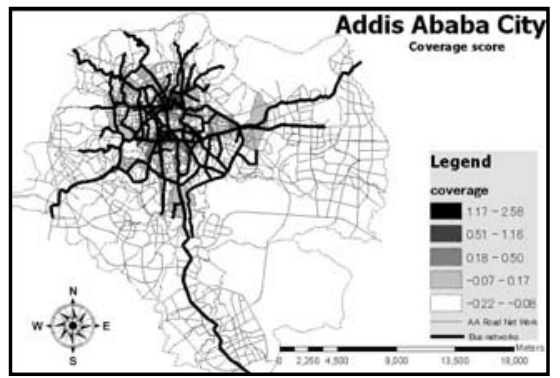

Figure 9. Frequency Scores

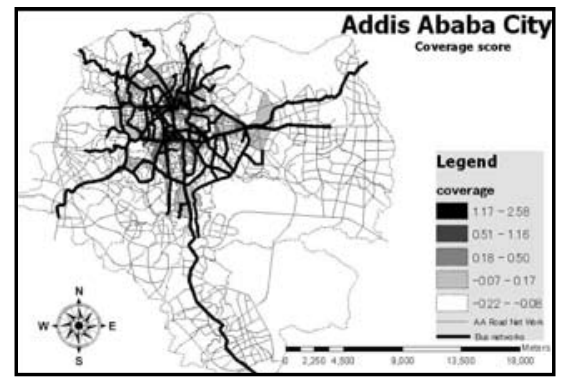

Figure 8. Coverage Scores

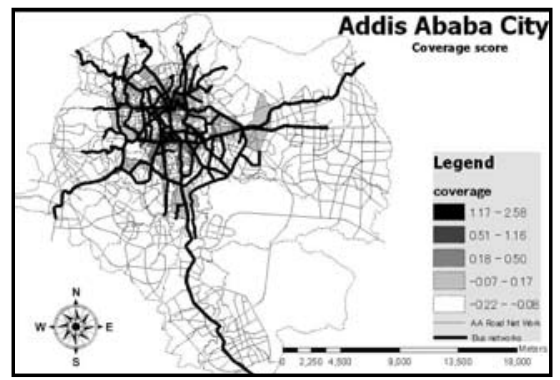

Figure 10. Overall CIBA Scores

\section{Indexing the Route Design Parameters}

Recalling the objective functions of maximizing route coverage and minimizing route overlapping, the indexing process is performed in such a way that, the larger the population, the higher the score, and the larger the coefficient of bus route parameters, the smaller the score assigned to the TAZ (see Table 1). 
Table 1. Indexing TAZ with Objective Functions

\begin{tabular}{|c|c|c|c|c|c|c|}
\hline \multicolumn{3}{|c|}{ Maximizing Trip Coverage } & \multicolumn{4}{|c|}{ Minimizing Bus Route Overlapping } \\
\hline $\begin{array}{l}\text { TAZ } \\
\text { score }\end{array}$ & Population & Workers & $\begin{array}{l}\text { TAZ } \\
\text { score }\end{array}$ & $\begin{array}{c}\text { Bus } \\
\text { Capacity }\end{array}$ & $\begin{array}{c}\text { Bus } \\
\text { Coverage }\end{array}$ & $\begin{array}{c}\text { Bus } \\
\text { Frequency }\end{array}$ \\
\hline 1 & $<10000$ & $<1000$ & 5 & $<4.5$ & $<4.5$ & $<4.5$ \\
\hline 2 & $10000-25000$ & $1000-3000$ & 4 & $4.5-5.5$ & 4.5-5.5 & $4.5-5.5$ \\
\hline 3 & $25000-40000$ & $3000-5000$ & 3 & $5.5-6.5$ & $5.5-6.5$ & $5.5-6.5$ \\
\hline 4 & $40000-55000$ & $5000-7000$ & 2 & $6.5-7.0$ & $6.5-7.0$ & $6.5-7.0$ \\
\hline 5 & $55000+$ & $7000+$ & 1 & $7+$ & $7+$ & $7+$ \\
\hline \multicolumn{7}{|c|}{$\begin{array}{l}\text { Maximization } \\
\text { Total population=IF(Tazi>55000,"5",IF(Tazi >40000,"4", IF(Tazi > 25000,"3",IF(Tazi >10000,"2",'1")))) } \\
\text { Working population=IF(Tazi >7000,"5",IF(Tazi >5000,"4", IF(Tazi >3000,"3",IF(Tazi >1000,"2,"'1"))) }\end{array}$} \\
\hline $\begin{array}{l}\text { Minin } \\
\text { Capa } \\
>4.5 \text {," }\end{array}$ & $\begin{array}{l}\text { overage, and fr } \\
\text { )) }\end{array}$ & $y=I F($ Tazi $>$ & ,IF(Taz & $6.5,2$ ", IF(7 & $>5.5,{ }^{\prime \prime}, 1$ & \\
\hline
\end{tabular}

\section{Impedance Coefficient}

Once the scores for the population and bus route parameters are assigned to each $T A Z$, adding up the scores provides the coefficient of that TAZ, $\mathbf{S}_{\mathbf{z}}$. Now each TAZ with a higher population and lower transit availability receives a high score, and vice versa. The next step is assigning the scores to the standard street links for bus transportation in each TAZ, $\mathbf{S}_{i}$. If the entire link belongs to the zone, the full value is assigned, but if the link is shared by two TAZs, the average of the value is assigned. Based on the assigned scores, the impeded length can be calculated as follows:

$$
\mathrm{C}_{\mathrm{i}}=\left(\mathrm{S}_{\max } / \mathrm{S}_{\mathrm{i}}\right) * l_{\mathrm{i}}
$$

where:

$$
\begin{array}{ll}
\mathrm{S}_{\max } & \text { is the maximum value of } \mathrm{S}_{\mathrm{i}} \text { for all segments } \\
\mathrm{S}_{\mathrm{i}} & \text { is the optimization score of segment } i \\
\mathrm{l}_{\mathrm{i}} & \text { is length of the segment } i \text { in kilometers } \\
\left(\mathrm{S}_{\max } / \mathrm{S}_{\mathrm{i}}\right) & \text { represents the impedance coefficient }
\end{array}
$$




\section{Table 2. TAZ Scores and Impendence Coefficient}

\begin{tabular}{|l|l|c|c|c|c|c|c|c|c|c|c|c|c|}
\hline $\begin{array}{l}\text { TAZ } \\
\text { No. }\end{array}$ & $\begin{array}{l}\text { TAZ } \\
\text { Name }\end{array}$ & Pop. & Index & $\begin{array}{l}\text { Work. } \\
\text { Pop. }\end{array}$ & Index & $\begin{array}{l}\text { Capa- } \\
\text { city }\end{array}$ & $\begin{array}{l}\text { Cove- } \\
\text { Index } \\
\text { rage }\end{array}$ & $\begin{array}{l}\text { Freq- } \\
\text { Index }\end{array}$ & $\begin{array}{l}\text { Uenctal } \\
\text { Index }\end{array}$ & $\begin{array}{l}\text { Impedance } \\
\text { index }\end{array}$ & Coefficient \\
\hline 1 & W01K01 & 9371 & 1 & 2901 & 2 & 4.535 & 4 & 4.789 & 4 & 4.485 & 5 & 16 & $\mathbf{1 . 5 0}$ \\
\hline 2 & W01K03 & 7363 & 1 & 2280 & 2 & 4.891 & 4 & 4.967 & 4 & 5.708 & 3 & 14 & $\mathbf{1 . 7 1}$ \\
\hline 3 & W01K04 & 11379 & 2 & 3523 & 3 & 5.225 & 4 & 6.072 & 3 & 6.080 & 3 & 15 & $\mathbf{1 . 6 0}$ \\
\hline 4 & W01K05 & 6024 & 1 & 1865 & 2 & 5.453 & 4 & 5.778 & 3 & 5.278 & 4 & 14 & $\mathbf{1 . 7 1}$ \\
\hline 5 & W01K06 & 8032 & 1 & 2487 & 2 & 4.749 & 4 & 4.605 & 4 & 4.245 & 5 & 16 & $\mathbf{1 . 5 0}$ \\
\hline$\ldots$ & $\ldots$ & $\ldots$ & $\ldots$ & $\ldots$ & $\ldots$ & $\ldots$ & $\ldots$ & $\ldots$ & $\ldots$ & $\ldots$ & $\ldots$ & $\ldots$ & $\ldots$ \\
\hline 302 & W21K04 & 8400 & 1 & 3333 & 3 & 7.691 & 1 & 6.282 & 3 & 7.701 & 1 & 9 & $\mathbf{2 . 6 7}$ \\
\hline 303 & W21K19 & 4721 & 1 & 1873 & 2 & 5.652 & 3 & 4.979 & 4 & 6.184 & 3 & 13 & $\mathbf{1 . 8 5}$ \\
\hline 304 & W21K20 & 4721 & 1 & 1873 & 2 & 4.700 & 4 & 4.846 & 4 & 4.882 & 4 & 15 & $\mathbf{1 . 6 0}$ \\
\hline 305 & W23K08 & 9005 & 1 & 1574 & 2 & 4.928 & 4 & 4.381 & 5 & 5.097 & 4 & 16 & $\mathbf{1 . 5 0}$ \\
\hline 306 & W23K09 & 7771 & 1 & 1359 & 2 & 4.601 & 4 & 4.854 & 4 & 4.721 & 4 & 15 & $\mathbf{1 . 6 0}$ \\
\hline 307 & W23K10 & 3735 & 1 & 653 & 1 & 6.603 & 2 & 4.540 & 4 & 5.097 & 4 & 12 & $\mathbf{2 . 0 0}$ \\
\hline 308 & W23K14 & 23200 & 2 & 4056 & 3 & 4.333 & 5 & 4.261 & 5 & 4.101 & 5 & 20 & $\mathbf{1 . 2 0}$ \\
\hline
\end{tabular}

\section{Optimized Route}

The final step is to carry out the GIS best-route finding analysis with the origin (urban center) and destination (expansion zone) that satisfies the following equation:

$$
\min \left\{\sum_{l=O_{l}}^{D_{l}} C_{i}\right.
$$

The origin and destination are selected based on the O-D data collected by the ERA in 2004. The methodology proposed in this study can be applied to any given origin and destination by transit operators or government planning officials. According to the ERA O-D data, high bus trips originate from one of the urban centers and are destined to one of the expansion suburbs where urban development is being undertaken. The Network Analyst extension of the ArcGIS software is implemented for route-searching routines, giving the calculated impeded length as the weight of the street link. According to the output, the proposed route satisfies the optimum fulfillment of the objective functions when compared to the shortest path. An illustrative example is presented in Figure 11. 


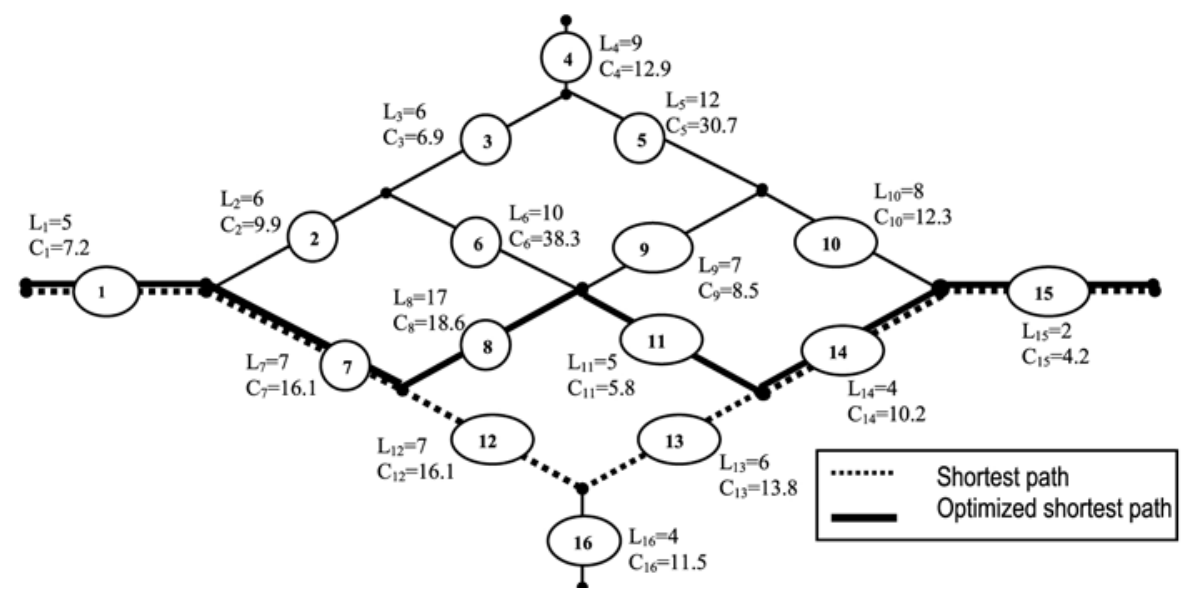

\begin{tabular}{c|cccc}
\hline Route & $\begin{array}{l}\text { Hypothetical } \\
\text { Length } \\
\left(\boldsymbol{L}_{\boldsymbol{i}}\right)\end{array}$ & $\begin{array}{l}\text { Hypothetical } \\
\text { Optimization Score } \\
\left(\boldsymbol{S}_{\boldsymbol{i}}\right)\end{array}$ & $\begin{array}{l}\text { Impedance } \\
\text { Coefficient } \\
\left(\boldsymbol{S}_{\max } \boldsymbol{S}_{\boldsymbol{i}}\right)\end{array}$ & $\begin{array}{l}\text { Impedance } \\
\text { Length } \\
\left(\boldsymbol{C}_{\boldsymbol{i}}\right)\end{array}$ \\
\hline $\mathbf{1}$ & 5 & 16 & 1.4 & 7.2 \\
$\mathbf{2}$ & 6 & 14 & 1.6 & 9.9 \\
$\mathbf{3}$ & 6 & 20 & 1.2 & 6.9 \\
$\mathbf{4}$ & 9 & 16 & 1.4 & 12.9 \\
$\mathbf{5}$ & 12 & 9 & 2.6 & 30.7 \\
$\mathbf{6}$ & 10 & 6 & 3.8 & 38.3 \\
$\mathbf{7}$ & 7 & 10 & 2.3 & 16.1 \\
$\mathbf{8}$ & 17 & 21 & 1.1 & 18.6 \\
$\mathbf{9}$ & 7 & 19 & 1.2 & 8.5 \\
$\mathbf{1 0}$ & 8 & 15 & 1.5 & 12.3 \\
$\mathbf{1 1}$ & 5 & 20 & 1.2 & 5.8 \\
$\mathbf{1 2}$ & 7 & 10 & 2.3 & 16.1 \\
$\mathbf{1 3}$ & 6 & 10 & 2.3 & 13.8 \\
$\mathbf{1 4}$ & 4 & 9 & 2.6 & 10.2 \\
$\mathbf{1 5}$ & 2 & 11 & 2.1 & 4.2 \\
$\mathbf{1 6}$ & 4 & 8 & 2.9 & 11.5 \\
\hline
\end{tabular}

$\mathrm{L}_{\mathrm{i}}=$ Actual length

$\mathrm{C}_{\mathrm{i}}=$ Impedance length $=\left(\mathrm{S}_{\max } / \mathrm{S}_{\mathrm{i}}\right) * \mathrm{Li}$

$\mathrm{S}_{\max }=$ Maximum value of $\mathrm{S}_{\mathrm{i}}$ for all segments

$\mathrm{S}_{\mathrm{i}}=$ Optimization score of link "i" comprising maximum population, minimum bus route coverage, bus frequency, and capacity (Pop. index +working pop. index + Coverage index + frequency index+ capacity index; see Table 1 for how the indexing is done)

Optimized path is the shortest route using IMPEDANCE LENGTH $\left(\mathrm{C}_{\mathrm{i}}\right)$ of street links as a weight for the link (bus routes in the place where there is high demand)

Shortest path is the shortest route using ACTUAL LENGTH of the street links as a weight for the link

\section{Figure 11. Example of Shortest and Optimized Routes}




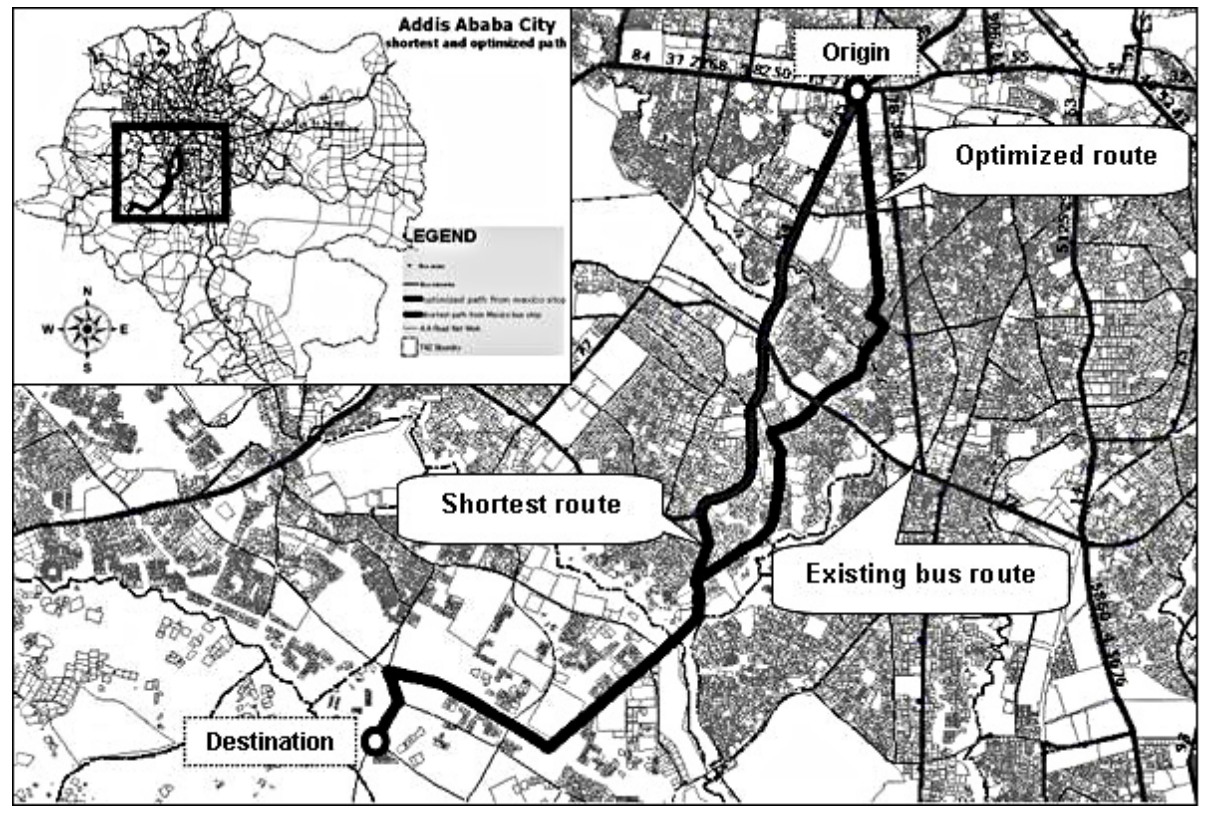

Figure 12. Actual GIS Output of Shortest and Optimized Path

\section{Route Evaluation}

Both transit operators and passengers prefer shorter and faster routes to reduce operating costs and in-vehicle time. Often, to reduce access impedence, tortuous routes are constructed, although they are likely to increase both in-vehicle time and operating cost (Chien et al. 2001). However, according to the GIS output of this research, the length of the optimized path is $7.8 \mathrm{~km}$, which has no significant difference to the shortest path $(7.1 \mathrm{~km})$; the new optimum route meets the criteria of increasing coverage and reducing route duplication, whereas the shortest path overlapped existing routes (see Figure 12). The change in each TAZ's level of bus service is analyzed to evaluate the effect of the added route. All service intensity parameters have shown a change in response to the new route. With the addition of more routes, the level of TAZ would increase, especially for TAZs in periphery areas, which exhibited below average scores. Those TAZs show an increase with regard to better capacity, coverage, and frequency scores (Figure 13). 


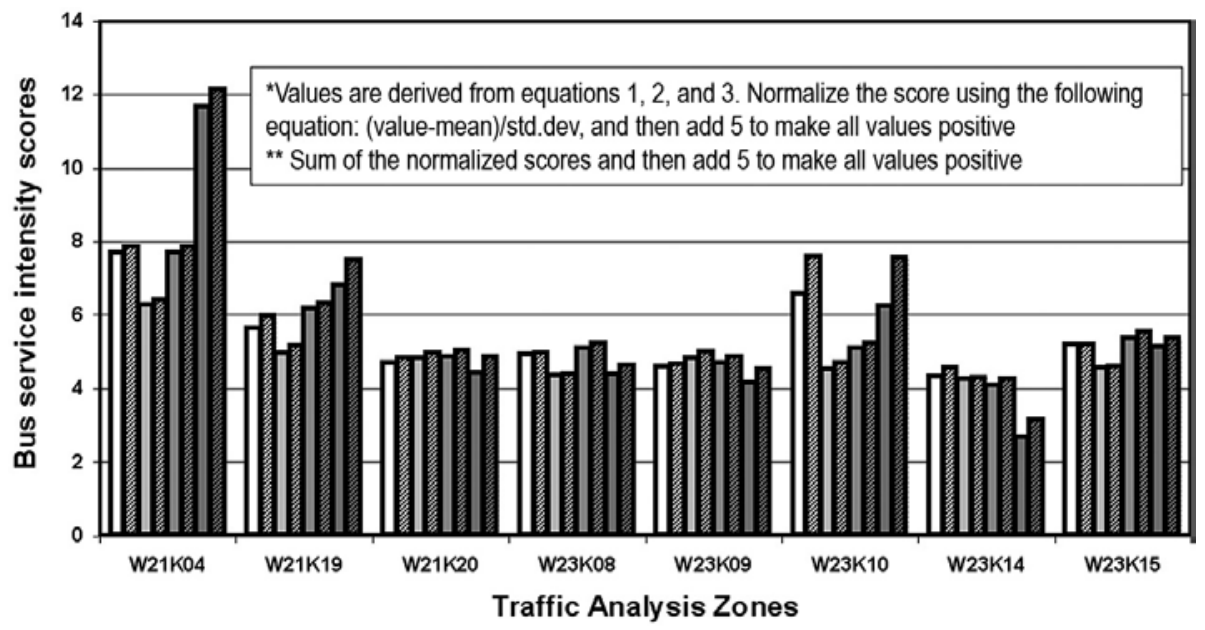

\begin{tabular}{|c|c|c|c|}
\hline 口Bus capacity before* & Bus capacity after* & $\square$ Bus coverage before* & Bus coverage after* \\
\hline quency before* & Q Bus frequency after ${ }^{*}$ & $\square$ Overall score before & D Overall score after ${ }^{* *}$ \\
\hline
\end{tabular}

\section{Figure 13. Comparison of Bus Service Intensity Before and After Route Addition}

\section{Conclusion}

Although public transit provides a relatively small portion of the total travel, it provides a much larger portion of particular types of travel (e.g., suburb commuters to the city center) and is an effective solution to certain transportation problems. It is most suitable for medium-distance trips in urban areas or on any corridor with adequate demand and as an alternative mode for travelers who, for any reason, cannot use a private automobile. For suburb commuters traveling to the city center for different purposes, the integrated public transportation route is essential. The route design procedure requires consideration of multicriteria parameters to produce an optimum route. The shortest route is not always the optimum route from the transit operator's or traveler's points of view. This research focuses on the application of GIS for bus route design with defined route design objectives. It follows simple procedures using the GIS powerful analysis capability. The unique feature of this study is the minimization of route overlapping so as to provide routes to underserved areas. For situations like Addis Ababa, where horizontal urban expansion is prevailing and several constraints for transit service development exist, the optimized route to link the urban centers with expansion areas 
is important. The methodology and results of this study would be useful for bus companies, municipal governments, and transit developers that seek to take part in the transit development of the city.

\section{References}

Abkowitz M., P. D. M. Cheng, and M. Lepofsky. 1990. Use of Geographic Information Systems in managing hazardous materials shipments. Transportation Research Record 1261: 35-43.

Ashish, Verma, and S. L. Dhingra. 2003. GIS for identification of demand-oriented urban rail transit corridor. Map India.

Chien, Steven, Branislav V. Dimitrijevic, and Lazar N. Spasovic. 2001. Bus route planning in urban grid commuter networks. TRB 80th Annual Meeting, Washington DC.

Ethiopian Road Authority (ERA). 2005. Urban transport study and preparation of pilot project for Addis Ababa. Consulting Engineering Services (India) Private Limited and SABA Engineering Private Limited Company, Addis Ababa, Ethiopia.

Kuswara, Ramalis Subandi Prihandana, and Rian Wulan Desriani. 2006. Characteristics of urban development and commuters in metropolitan Bandung. Map Asia.

Mintesnot, G., and S. Takano. 2006. Application of logical planning model for public transportation improvement programs in the city of Addis Ababa. Studies in regional science. Journal of JSRSAI 36, 3: 663-682

Office of the Revision of Addis Ababa Master Plan (ORAAMP). April 2002. Project proposal for Addis Ababa transport sector. Addis Ababa, Ethiopia.

Osegueda, Roberto, Alberto Garcia-Diaz, Suleiman Ashur, Octavio Melchor, SungHo Chang, Cesar Carrasco, and Ahmet Kuyumcu. 1999. GIS-based network routing procedures for overweight and oversized vehicles. Journal of Transportation Engineering 125, 4.

Ramirez, A. I., and Senevirante P. N. 1996. Transit route design applications using Geographical Information Systems. Transportation Research Record 1557: $10-14$. 
Rood, Timothy. 1998. The local index of transit availability, an implementation manual. Local Government Commission.

Sekhar, S. V. C., Wen Long Yue, and M. A. P. Taylor. 2003. An approach to transit path design using GIS. Journal of Eastern Asia Society for Transportation Studies 5: 414-425.

Sulijoadikusumo, G. S., and L. K. Nozick. 1998. Multi-objective routing and scheduling of hazardous materials shipments. Transportation Research Record 1613: 96-104.

TDM online encyclopedia. Updated November 2006. Victoria Transport Policy Institute. http://www.vtpi.org/tdm/.

Transport Research Board. 1995. Bus route evaluation standards, A synthesis of transit practice 10. Washington, DC: National Academy Press.

Transport Research Board. 2003. Transit capacity and quality of service manual, 2nd ed. TCRP Report 100. Washington DC.

\section{About the Authors}

Mintesnot Gebeyehu (mintesnot@gmail.com) is a research fellow in DLR, Transportation Research Institute, Germany. He holds a master's and PhD degree in urban engineering and planning from Hokkaido University, Department of Urban and Environmental Engineering, Japan. His research focuses on urban land use and public transportation planning and policy.

SHIN-EI TAKANO (shey@eng.hokudai.ac.jp) is an associate professor of transportation planning and construction management at Hokkaido University in the Department of Urban and Environmental Engineering. His research focuses on public transportation planning, construction management, and tourism transport management. He has participated in numerous national and local transportation projects and has reviewed several research papers for refereed journals. 